\title{
Ciclos sistêmicos do capitalismo, Estado e dinâmica federativa: uma discussão teórica
}

\section{Systemic cycles of capitalism, State and federative dynamics: a theoretical discussion}

\section{Luciana Pazini Papi Klei Medeiros}

\section{Resumo}

O artigo tem como objetivo apresentar uma discussão sobre a relação entre os ciclos sistêmicos do capitalismo e as dinâmicas federativas dos Estados periféricos. Parte-se do pressuposto que as federaçóes não são forjadas unicamente por suas rotas institucionais internas, como sustentam as teorias institucionalistas, mas sofrem influências dos ciclos sistêmicos do capitalismo. Dessa maneira, processos de centralização e descentralização dos Estados responderiam ao movimento cíclico capitalista que impóe modelos descentralizadores e liberais alternados por modelos de Estados ativos e coordenadores, impondo mudanças no funcionamento de federaçóes. Nos anos 1980, se difundiu a visão de que a descentralização significaria um instrumento de eficiência administrativa, accountability e democratização. Aqui argumenta-se que a descentralização não carrega consigo um valor intrínseco e seus efeitos dependem do Estado que se quer reformar e dos contextos sócio históricos que lhes atribuem sentido.

\section{Palavras-chave}

Estado; Federalismo; Ciclos Sistêmicos; Centralização; Descentralização.

\section{Abstract}

The article aims to present a discussion about the relationship between the systemic cycles of capitalism and the federative dynamics of peripheral states. It is assumed that federations are not forged solely by their internal institutional routes, as institutionalist theories hold, but they are influenced by the systemic cycles of capitalism. In this way, processes of state's centralization and decentralization would respond to the cyclical capitalist movement that imposes decentralizing and liberal models alternated by models of active states and coordinators, imposing changes in the functioning of federations. In the 1980s, it was said that decentralization would mean an instrument of administrative efficiency, accountability, and democratization. Here it is argued that decentralization does not carry with it an intrinsic value and its effects depend on the State that one wants to reform and the socio-historical contexts that give them meaning.

\section{Keywords}

State; Federalism; Systemic Cycles; Centralization; Decentralization. 


\section{Introdução}

Tradicionalmente, o debate sobre Estado ${ }^{1}$, federalismo e políticas públicas centra-se na análise dos processos institucionais internos como definidores de suas constituições e formatos. Entretanto, uma parte significativa da dinâmica estatal - a condução do desenvolvimento, o seu tamanho e o seu papel sobre economia e sociedade - são explicados pela lógica do capitalismo internacional. Se por um lado, nas relações internacionais, as diversas teorias sobre o sistema mundial apresentam elementos capazes de compreender a questão das hegemonias e aspectos estruturais,

\footnotetext{
${ }^{1}$ Apesar do conceito corrente de Estado atrelar-se à tradição weberiana - em que o mesmo é entendido como sistema de poder institucional, onde os conflitos são canalizados e resolvidos e as instituiçóes definidas e aplicadas (BRESSER-PEREIRA, 2009, p. 16), nesse artigo adotamos a definição vinculada à visão marxista e neomarxista presente em autores como Lênin [1917] (1965), Nicos Poulantzas [1968] (2007), Miliband (1972), Arrighi (1997). Nessa linha interpretativa a dominação do homem sobre o homem, a partir do uso da violência "legítima" (como cunhado por Weber), não é explicada por um processo descolado da dominação de classe. Ao contrário, o Estado é o representante principal da hegemonia da classe capitalista, aquele que garante a perpetuação de seus interesses. Avançando no conceito para compreender as peculiaridades do Estado na periferia, o que serve especialmente para os fins desse artigo, a contribuição de Lênin e dos neomarxistas foi fundamental para situar a noção de hegemonia no contexto de um sistema mundial. Ou seja, para tais autores, o Estado nessas realidades permanece sendo o reflexo das relaçóes de classe, mas tal classe dominante não se localiza necessariamente na nação. Conforme Carnoy (1988, p. 15) sintetiza: “o Estado no Terceiro Mundo se desenvolve em condiçóes diferentes das enfrentadas pelos países industriais avançados, principalmente devido ao papel histórico do capital estrangeiro na periferia e ao resultante enfraquecimento das burguesias locais. Essa fraqueza, por sua vez, dificulta o estabelecimento da hegemonia local e cria condições para o surgimento de regimes autoritários altamente coercitivos e burocráticos". Arrighi (1997), refletindo sobre a dinâmica do desenvolvimento, aporta uma explicação fundamental para se entender o perfil do Estado na periferia. Para o autor, a característica intrínseca do sistema global é a concentração de riqueza que se reflete na concentração do comando internacional. Trabalhando com a lógica da divisão internacional do trabalho, Arrighi (1997) sustenta que a natureza do sistema mundial é uma divisão entre centro, periferia, semiperiferia onde cabe aos primeiros o lugar privilegiado na produção de inovação, a introdução de novos métodos de produção, novas fontes de suprimento, novas formas de organização do trabalho que proporcionam ganhos expressivos. À periferia se subordina aos rumos determinados pelo centro, gozando de graus de liberdade relativos na orientação de seu desenvolvimento interno. Desta forma, as economias podem apresentar alguns momentos de melhoras nos indicadores econômicos, sociais, mas, em momentos de instabilidade, a experiência histórica mostra que prevalecem os interesses centralizados do grande capital, mediados pela interferência dos Estados nacionais. Portanto, existem limites estruturais ao desenvolvimento nacional dos países periféricos, no contexto de uma ordem global capitalista.
} 
por outro, elas dificilmente são associadas aos padrões estatais no nível doméstico, em especial aos desenhos institucionais.

Neste artigo pretende-se avançar no debate sobre a relação da dinâmica externa com a interna dos Estados, especificamente, observando os condicionantes dos ciclos sistêmicos nos formatos internos da divisão territorial do poder. Desta forma, apresentamos em um primeiro momento, uma visão alternativa sobre a dinâmica das federaçóes, postulando a tese de que, para se entender os processos de centralização e descentralização, não basta observar apenas a "arquitetura institucional", como sustenta a abordagem neoinstitucionalista, a partir do conceito de path dependence. Sem negar a importância de se mapear os legados institucionais e buscar entender o que cada país tem de permanente e específico em suas federaçóes, e como isso influencia os processos de repartição de poderes e competências em suas histórias, é necessário ir mais longe para compreender de que forma os processos econômicos, políticos e sociais (sobretudo externos) influenciam a dinâmica de centralização e descentralização das federações.

Nesse sentido, no artigo apresentamos a forma como as diversas teorias de ciclos sistêmicos explicam a retração e expansão dos Estados, visando a situar o debate sobre descentralização federativa dos anos 1980 e 1990 na lógica das mudanças capitalistas originadas nos anos 1970. Entendemos, igualmente, a mudança em prol de uma re-centralização federativa nos anos 2000, em diversos países da Américalatina, como uma tentativa dos Estados recuperarem o comando e a dianteira sobre os processos de desenvolvimento interno, dessa vez através de políticas sociais estratégicas, dado o processo de crise do modelo neoliberal vigente no centro.

Esse referencial, fundamental para analisar quaisquer mudanças políticas institucionais nos países periféricos, dado que o principal pressuposto dessas sociedades é sua relação intrincada com a dinâmica econômica e política do centro, tem sido preterido em escritos contemporâneos na Ciência Política que optam em geral pela análise dos grupos de poder internos e a conformação de instituições como condicionantes para a restante da vida social e política. Entretanto, defendemos que resgatar essa leitura teórico-metodológica, realizada por clássicos latino-americanos nos anos 1950 e 1960 - ligados à Comissão Econômica para a América Latina (CEPAL) e ao Instituto Superior de Estudos Brasileiro (ISEB), como Ignácio Rangel, Celso Furtado, André Gunder Frank, para citar alguns ${ }^{2}$, assim como, pelos teóricos

2 Os estudos desenvolvidos pelos autores citados, de forma comum buscam explicar o desenvolvimento/subdesenvolvimento pela relação centro-periferia, lançando mão de interpretação 
neomarxistas como Giovanni Arrighi, Immanuel Wallerstein e Samir Amim, torna-se central para situar a compreensão da vida social e política brasileira à realidade que lhe dá origem - o sistema mundo.

Feito esse panorama teórico-histórico na primeira seção, a segunda seção analisa a relação teórica estabelecida no meio acadêmico entre o paradigma liberal clássico e o elemento normativo em prol da descentralização federativa. Enquanto o tradicional Estado hobbesiano é associado a formas conservadoras, ineficientes, instáveis e autoritárias de governo, o liberalismo associa a descentralização à democratizaçáo, à existência de múltiplos atores, ao pluralismo e a um Estado mais eficiente. Até os anos 1970, entretanto, tal ideia clássica fica incubada, aguardando ser recuperada no contexto do neoliberalismo e do Consenso de Washington, que associa a descentralização federativa à responsabilidade fiscal governamental, à eficiência e ao princípio de redução da sobrecarga estatal. Nesta seção (um panorama amplo sobre os estudos de federalismo em sua lógica interna), será demonstrado que, mesmo que se queira estabelecer uma norma a respeito da qualidade que a descentralização garante ao Estado, esta náo pode ser uma regra, pois depende da área governamental de que se está tratando, da sua importância para as visóes de desenvolvimento em

econômica a partir das leis do capitalismo, do marxismo ou do estruturalismo. Os esforços dos autores foram no sentido de compreender os efeitos da expansão do capitalismo central na periferia, a partir da noção de dependência - que segundo os autores, gerou impactos profundos na economia nacional dos países latino-americanos. Umas das consequências foi o crônico endividamento externo gerado pelas relaçôes de trocas desiguais e pela dominação do capital financeiro e bancário; a vocação agrárioexportadora em detrimento da industrialização; a desigualdade na apropriação do excedente econômico e a baixa capacidade de inversão das elites nacionais; a baixa socialização nacional dos benefícios do capitalismo e a superexploração do trabalho (MACHADO, 1999). Para reverter esse cenário, os autores sinalizam a importância da intervenção do Estado em áreas estratégicas para promover o desenvolvimento e a distribuição (BIELCHOWSKY, 2004). É importante salientar que a partir dos anos 1980, em função de novos acontecimentos na economia internacional, como a globalização, alguns autores como André Gunder Frank (1980), fazem uma revisão da teoria da dependência nos anos 1980, migrando para a teoria do sistema mundo. Em Reflections on the World Economic Crisis (1981), Gunder Frank afirma que não há como com se encerrar uma teoria sobre a dependência em si, sem conectá-la a uma análise global da acumulação. A partir daí vários estudiosos dedicam-se à elaboração de uma da teoria dos ciclos sistêmicos de acumulação, vislumbrando-o a partir da noção do desenvolvimento de longo prazo do sistema-mundo capitalista, combinando a perspectiva dos ciclos longos ou ondas longas de Nikolai Kondratiev com os ciclos históricos de Fernand Braudel. Essa combinação conforma as bases da teoria do sistema-mundo - trabalhada por Giovanni Arrighi, Samir Amin e Immanuel Wallerstein. 
determinado momento histórico e da capacidade financeira e de arrecadação dependente da dinâmica capitalista internacional.

Em termos metodológicos, o trabalho caracteriza-se como um ensaio teórico, dada sua natureza reflexiva e interpretativa acerca do fenômeno político-social em tela: as dinâmicas institucionais (federativas) e seus motores causais. No centro do ensaio valorizamos os aspectos relacionados às mudanças qualitativas que ocorrem no federalismo, especialmente nos processos de centralização e descentralização, sem explorar em profundidade a dimensão empírica ${ }^{3}$, uma vez que, na essência do trabalho, o que se pretende é problematizar as visōes correntes que sustentam a compreensão do fenômeno.

\section{A teoria dos ciclos sistêmicos: elementos de mudança sob os processos de expansão e retração do Estado}

Teóricos da "escola dos Analles", como Fernand Braudel e outros do chamado neo-marxismo, como Imanuel Wallerstein, Giovanni Arrighi, chamaram a atenção para a transformação dos Estados nacionais a partir da mudança sistêmica na qual se coadunam aspectos econômicos e políticos externos e internos. Os autores evidenciaram como as grandes transformaçôes históricas capitalistas no centro têm resultado em rearranjos não apenas geopolíticos (hegemonias), mas dos próprios Estados nacionais centrais e periféricos. Tais mudanças seriam desencadeadas, sobretudo, por períodos de crise e reestruturação da economia capitalista mundial ${ }^{5}$.

A origem de tal processo, segundo os mesmos autores, foi gestada na Europa antes mesmo da existência do capitalismo e da formação do Estado moderno. Conforme Wallerstein (1974) e Anderson (2004), foi a crise do sistema feudal no século XIV e seu esgotamento como sistema econômico e político que alçou como solução a formação do capitalismo "primitivo" e do Estado moderno ocidental, com seu aparato jurídico e coercitivo. Desde então, conforme assinalou Braudel (1984, p.

\footnotetext{
${ }^{3} \mathrm{O}$ artigo aqui apresentado derivou das reflexóes teóricas resultantes da pesquisa de doutorado desenvolvido pela autora (PAPI, 2017), momento em que a dimensão empírica foi explorada em profundidade.

${ }^{4}$ Foi um movimento historiográfico nascido em 1929 em torno de um periódico francês. Baseada na perspectiva de história de longa duração, teve como grandes expoentes Marc Bloch e Fernand Braudel. ${ }^{5}$ Tais teóricos fizeram uso de instrumentais da economia para entender as relaçóes políticas entre as naçóes, utilizando deliberadamente os modelos de crises cíclicas do capitalismo, originalmente cunhado por Marx e posteriormente apropriado por outras teorias, como a dos ciclos longos e curtos do capitalismo, formulada por Kondratiev, que divide os ciclos capitalistas por ondas longas e curtas derivadas das flutuaçóes de longo prazo no preço das mercadorias.
} 
92), "tal metamorfose na Europa se transformou no grande modelador da história mundial”, e assim se sucedeu: a cada ciclo do capitalismo, uma nova solução política e econômica foi lançada no cenário internacional para o centro e a periferia.

Giovanni Arrighi (1996) e Arrighi e Silver (2001), partindo da noção de "ciclos sistêmicos" de acumulação ${ }^{6}$, demonstraram a alternância de hegemonias de determinadas nações durante sequências históricas, em que se dá a expansão do desenvolvimento econômico e tecnológico seguida por um período de crise sinalizadora e queda. Essas crises são responsáveis por alçar novas hegemonias, trazendo padróes e características políticas, econômicas e sociais distintas para centro e periferia. De acordo com o autor, houve quatro ciclos sistêmicos na história moderna: o primeiro liderado por Gênova e Veneza; o segundo liderado pela Holanda; o terceiro pela Inglaterra e, finalmente, Estados Unidos. Recentemente o autor trabalha com o declínio de hegemonia norte-americana e ascensão de novos atores com liderança internacional em um sistema cada vez mais multipolar (ARRIGHI, 2008).

Seguindo a mesma orientação analítica de ciclos sistêmicos, e enfatizando a relação centro-periferia, um grupo de intelectuais latino-americanos dos anos 1950 e 1960 ligados à CEPAL e ao ISEB, buscou entender as estruturas e processos que levaram ao subdesenvolvimento dos países periféricos.

Entre os mais notáveis intelectuais, Celso Furtado e Ignácio Rangel mostraram como, após o processo histórico específico ligado à difusão do capitalismo europeu, configuraram-se estruturas econômico-sociais e políticas duais (setores, regióes modernas e arcaicas, momentos históricos distintos) na periferia, que respondem aos movimentos de fluxo e refluxo da economia externa de acordo com a formação econômica social interna. Dessa maneira, não apenas as atividades econômicas locais exigiram reconfigurações, mas as próprias estruturas políticas e

\footnotetext{
${ }^{6}$ Para a definição de ciclo sistêmico de acumulação, Arrighi fundamenta-se em Braudel e recorre ao esquema de Marx para realizar uma analogia da flexibilização do capital. Arrighi afirma: "o aspecto central deste padrão é a alternância de épocas de expansão material (fases DM de acumulação de capital) com fases de renascimento e expansão financeiros (fases MD'). Nas fases de expansão material, o capital monetário "coloca em movimento" uma massa crescente de produtos (que inclui a força de trabalho e dádivas da natureza, tudo transformado em mercadoria); nas fases de expansão financeira, uma massa crescente de capital monetário "liberta-se" de sua forma mercadoria, e a acumulação prossegue através de acordos financeiros (como na fórmula abreviada de Marx, DD’). Juntas, essas duas épocas, ou fases, constituem um completo ciclo sistêmico de acumulação" (ARRIGHI, 1996, p. 6).
} 
estatais se reconfiguraram a partir das mudanças desencadeadas pelos ciclos internacionais ${ }^{7}$.

Por essa lógica teórica, as federações, que podem ser compreendidas como: "uma forma de organização de Estado que distribui poder verticalmente entre as unidades federadas, de tal modo que diferentes níveis de governo têm autoridade sobre a mesma população e território" (LIJPHART, 2003, p. 214), a despeito das rotas institucionais específicas que lhes dão origem, estariam sujeitas a processos de mudanças desencadeados por movimentos externos.

Apesar da literatura institucionalista especialmente na vertente histórica, apontar que a sequência dos acontecimentos é importante para compreender a formatação das instituições, tal como uma estrutura que condiciona "o jogo político" (HALL e TAYLOR, 2003), ao reforçar as tendências de reprodução e resistência institucional, ela se mostra frágil para explicar as mudanças.

Com efeito, se o conceito de instituição política, seguindo a lógica de Path dependence $e^{8}$, aponta para um conjunto de características relativamente duradouras da vida política e social (regras, normas, procedimentos), nas quais comportamento e estrutura não podem ser alterados facilmente, como pensar a mudança ou movimento nas instituições que não derivam de sua própria rota?

Trazendo esse debate para o campo de estudos sobre federações, há na literatura mais clássica um reflexo dessa tendência. Elazar (1991), um dos expoentes a trazer a ideia de que os modelos dos Estados derivavam de aspectos particulares da formação de cada sociedade, tratou o conceito como derivativo de uma aspiração dos

\footnotetext{
${ }^{7}$ Aliás, ambos os autores - desenvolvimentistas - reforçavam o papel central dos Estados em países periféricos na superação do subdesenvolvimento. Ou seja, deveriam eles, a partir de uma atuação deliberada e por meio de estruturas de planejamento, construir modernas estruturas estatais e naçóes economicamente desenvolvidas (BIELCHOWSKI, 2004).

${ }^{8}$ Esse conceito foi desenvolvido pela vertente do neoinstitucionalismo histórico e vincula-se a uma concepção particular do desenvolvimento histórico das naçóes. O conceito de path dependence sinteticamente significa que eventos passados (momento histórico particular) influenciam variaçóes nas sequências sociopolíticas, ou nos resultados dos sistemas políticos de sociedades específicas. Trata-se de afirmar, simplificadamente, que a história, a trajetória das instituiçóes é fundamental para compreender a situação presente. Especificamente, Pierson (2004), um dos principais autores a desenvolver o conceito, afirma que, além do tempo, a ordem como surgem e se combinam os fatos históricos condiciona decisóes e políticas posteriores, ao encorajar as forças sociais a se organizar segundo certas orientaçôes e não a outras. Desta forma, quando um país inicia uma trajetória institucional, torna muito alto o custo de revertê-la, sendo alta a probabilidade de seguir o mesmo caminho trilhado originalmente conforme o tempo avança.
} 
grupos sociais por forjar um pacto de convivência pacífica diante das diversidades. $\mathrm{Ou}$ seja, valorizando aspectos dogmáticos para explicar a adoção da fórmula federativa, após esse pacto originário, caberia às Constituiçôes garantir a partilha de poder entre as partes, equilibrando os processos de centralização e descentralização (ELAZAR, $1991)^{9}$.

Entretanto, autores mais contemporâneos e de vertentes mais realistas, como Watts (2006), pontuaram a necessidade de se observar o funcionamento concreto das federaçôes a partir de aspectos que extrapolem as origens fundadoras e os aspectos legais que as sustentam. Conforme o autor,

As relaçôes entre a sociedade, instituiçôes políticas e processos políticos não são estáticas estando em contínua interação. A compreensão dos sistemas federais, assim como o desenho dos mesmos (centralizados ou descentralizados) são influenciados não apenas pelas forças sociais vigentes no momento da adoção, mas pelas superestruturas políticas e as conexôes entre procedimentos e práticas politicas. É na diversa interação entre forças sociais, constituições escritas e práticas dos governos onde se fundamenta a compreensão da natureza e efetividade dos sistemas federais (WATTS, 2006, p. 109).

A partir dessas reflexões, a noção de dinâmica federativa e seus movimentos de centralização e descentralização são postos em um novo panorama interpretativo que permite estabelecer a relação entre os elementos sociais e históricos estruturantes (como a gênese da construção das sociedades) e os processos políticos que incidem sobre eles - tais como a relação centro-periferia.

A esse respeito, Bresser-Pereira (2009), aplicando o modelo de ciclos para entender os padrões de mudança do Estado em face dos movimentos do mercado,

9 Elazar foi um dos pioneiros nos estudos sobre o federalismo. Tendo estudado o caso norteamericano, considerou o federalismo em essência como uma forma superior de dividir a autoridade política e o poder no interior de um Estado de forma a se garantir a autonomia e a convivência pacífica entre as partes que pactuam e consolidam tais princípios em uma constituição. A definição mais simples é a de autogoverno, regra compartilhada que envolve algum tipo de (1) vinculaçáo contratual estabelecida em caráter permanente; (2) partilha de poder considerando a questão da soberania das partes; (3) sem a substituição ou diminuição dos laços orgânicos anteriores ao momento de integração; e (4) resolvendo problemas de organização e integração política de maneira menos conflituosa (ELAZAR, 1991). 
oferta um panorama interpretativo para compreender a expansão e retração do Estado que interferem nessas instituiçóes. Conforme o autor,

[...] a intervenção do Estado segue um padrão cíclico. Ao responder aos fracassos do mercado, como nos anos 1920 e 1930, ele aumenta seu escopo. No entanto, nos anos 1970 [...] com a crise fiscal e a aceleração da globalização abre-se espaço para a privatização e a desregulação do mercado (BRESSER-PEREIRA, 2009, p. 33-34).

Foi assim a alternância entre processos de expansão e retração da atuação do Estado durante a história ${ }^{10}$.

Com efeito, na crise de 1929, o modelo de laissez-faire vigente durante o século XIX sob a hegemonia do imperialismo britânico de livre-comércio (ARRIGHI, 1996) entra em declínio ${ }^{11}$ (desde o pós-I Guerra Mundial), cedendo espaço para um modelo de desenvolvimento coordenado pelo Estado em que as políticas de proteção ou bem estar social tornaram-se parte estratégica de um sistema sustentado na associação do capital ao trabalho e ao consumo de massas.

No centro, as saídas da crise passaram pelas ideias de John Maynard Keynes, que buscava construir uma nova era para o capitalismo baseada no pleno emprego e no consumo de massas. $\mathrm{Na}$ periferia, a saída da crise passou pelo modelo de inversão de importaçóes sustentadas nas ideias desenvolvimentistas que passaram pela

\footnotetext{
${ }^{10}$ Existiriam para o autor cinco formas históricas do Estado que se alteraram com o tempo: 1) o modelo autoritário patrimonial, gestado no absolutismo e do processo que lhe dá origem; 2) o Estado liberal do século XIX, em que vigorou o imperialismo britânico de livre-comércio (e na periferia a expropriação de tributos, mão-de-obra e recursos naturais por meio da articulação ou intervenção política, como no caso da Índia); 3) o Estado social democrático do século XX (1930-1970) sob liderança dos EUA, em que o desenvolvimento econômico carreado pelo Estado (Keynesianismo no centro e desenvolvimentismo na periferia) e a ampliaçáo de direitos sociais foram centrais para superar a crise pretérita de fins do século XIX; 4) o Estado social-liberal, em que as forças do mercado mais uma vez ganham força vis a vis ao Estado; se restringem direitos sociais em nome de uma ordem econômica e se promove a reforma do Estado, como já apontado extensamente no início do trabalho; 5) o Estado neo-desenvolvimentista dos países latino-americanos, em que houve a construção de uma estratégia alternativa de desenvolvimento pautada na retomada do crescimento econômico nacional com promoção de desenvolvimento social por meio da revalorização política do papel do Estado (BRESSER-PEREIRA, 2007; FIORI, 2007; DINIZ, 2007).

${ }^{11}$ Por conta do modelo de produção rígida e em larga escala baseado no consumo de massas, que leva à crise de superprodução e ao crash da bolsa de Nova York (HARVEY, 2005).
} 
formulação de teóricos como Ignácio Rangel, Celso furtado e Raul Prebisch (BIELCHOWSKI, 2004), de forte influência keynesiana, que adaptam seus princípios da economia política para países periféricos latino-americanos.

Com suas peculiaridades atreladas ao grau de desenvolvimento das sociedades em pauta, tais modelos econômicos e políticos se sustentavam em um papel ativo do Estado como interventor na economia (através da criação de bancos públicos, indústrias nacionais e infraestrutura) e como provedor de políticas de Bem-Estar Social (através de proteção ao emprego formal e assistência aos desvalidos e pobres). Ademais, tal sistema se estruturava em instituiçóes fortes e centralizadas com grandes estruturas de planejamento econômico (BRESSER-PEREIRA, 2009). Conforme salientou Martha Arretche (2002), referindo-se ao modelo de Estado vigente no Brasil nesse contexto, o Estado brasileiro aproximava-se mais de um modelo unitário do que de uma federação, dado o alto nível de centralização.

Após esses anos de crescimento, as décadas de 1980 e 1990 assinalam um período de novas crises e renovação do discurso liberal. A década de 1970 foi marcada por uma profunda crise de natureza econômica, energética e política que afetou tanto o centro quanto a periferia do sistema mundial. Entre as principais causas se encontra a crise do petróleo, representada pelo aumento do preço desse produto em 1973 e 1979, o que afetou a produção e comércio mundial (MILANI, 2014). Isso levou paulatinamente a uma redução das taxas de crescimento econômico nos países industrializados e nos países de industrialização recente, passando a afetar as políticas do Estado de Bem-Estar Social e a legitimidade do modelo político de desenvolvimento erguido no pós-II Guerra.

Ademais, diante do processo de fim da Guerra Fria, com a derrocada do bloco socialista, um conjunto de formulaçôes teóricas contribuiu para o desgaste e questionamento do modelo anterior de atuaçáo estatal. $\mathrm{O}$ modelo de gestáo do Estado centralizado e seu padrão de desenvolvimento (baseado na intervenção econômica e na produçáo de serviços) passaram a ser responsabilizados pela crise. Assim, um processo sistêmico, já observado na década de 1930, por exemplo, passa a ser explicado pelo mainstream internacional não pelas teorias das crises cíclicas do capitalismo, mas pela forma política dominante nos países de então, de forma a justificar as mudanças e as reformas do Estado.

O "Fim da História" (FUKUYAMA, 1992), a inevitabilidade da globalização proferida por Margareth Tatcher ("There Is No Alternative") (CHANG, 2008) e, por fim, as elaboraçóes do modelo de Estado neoliberal consubstanciados pelo Consenso 
de Washington ${ }^{12}$ encerraram o contexto teórico que legitimaria as mudanças ocorridas no cenário internacional das décadas de 1980 e 1990.

Como eixos estruturantes da proposta de reformas no centro da economiamundo, se postulou a necessária estabilização econômica, a abertura comercial e financeira como sustentáculo da globalização. Em relação ao Estado, foram feitas reformas administrativas e a readequação de órgãos e atividades estatais, o que abrangeu programas de privatizações, projetos de delegaçáo e descentralização encontrando referência teórica nas formulaçóes da New Public Management ${ }^{13}$ (PETERS, 2005).

$\mathrm{Na}$ periferia do sistema internacional, por sua vez, as formulações do Consenso de Washington foram o sustentáculo teórico à "necessária" saída da crise, indicado pelos países centrais aos em desenvolvimento (CHANG, 2008; DINIZ, 2007). Nesse contexto, as instituiçóes multilaterais, sobretudo o Banco Mundial e o FMI, passaram a se envolver em quase todas as áreas da política econômica e da agenda social do mundo em desenvolvimento, muitas vezes de maneira sobreposta e contraditória (HALL e MIDGLEY, 2004), orientando os rumos das reformas. Segundo Chang (2008, p. 31, grifo nosso),

Elas (instituiçóes de Breton Woods) passaram a controlar áreas como orçamento de governo, regulação industrial, definição do preço dos produtos agrícolas, regulamentação do mercado de trabalho, privatizações e assim por diante. Na década de 1990, houve grande passo nesta missão à medida que atrelavam esses condicionantes de governança à concessão de seus empréstimos. Isso implicou intervençôes em áreas que não eram imaginadas até então como a democracia a descentralização de governo $[\ldots]$.

12 Reunião realizada em Washington em 1989 entre funcionários do governo estadunidense e do Fundo Monetário Internacional (FMI) com o objetivo de formular uma espécie de receituário de políticas econômicas para a América Latina. Dentre as orientaçóes constavam a abertura unilateral das economias, privatizaçóes e reformas monetaristas e criação de um mercado autorregulável sem interferências do Estado.

${ }^{13} \mathrm{~A}$ O termo foi introduzido pela primeira vez por acadêmicos no Reino Unido e Austrália para descrever atividades dos governos na década de 1980 e vocalizava a ideia de tornar o serviço público mais eficiente usando modelos de gestão do setor privado. 
No caso da América Latina, houve a adoção, com maior ou menor intensidade, de tais orientaçóes. Os governos de centro-direita ${ }^{14}$ que governavam no período, dadas as suas peculiaridades, implementaram políticas e reformas em torno da abertura econômica, da privatização de empresas nacionais e por um conjunto de ações que buscaram integrar as economias à era da globalização (HARVEY, 2005). De maneira geral, todos os governos provocaram um efeito de minimização do papel do Estado no processo de desenvolvimento nacional.

$\mathrm{O}$ início do século XXI se inaugura ainda em meio à crise econômica. A adoçáo do modelo neoliberal, reinante durante a década de 1990, se mostrou incapaz de responder às crises cíclicas e estruturais do capitalismo contemporâneo. Diante da conjuntura de queda de crescimento dos países centrais ${ }^{15}$, da consolidação da China como nova superpotência no sistema internacional e da crescente relevância dos países emergentes em inúmeros fóruns internacionais (G-20 comercial, BRICS ${ }^{16}$ e IBAS $^{17}$ ) e em instituições multilaterais, como no FMI, aprofunda-se o movimento de multipolaridade apontado por Arrighi (1996).

Se, no centro, o refluxo do discurso neoliberal demora a perder força ${ }^{18}$, na periferia, sobretudo na América Latina, a eleição de governos de centro-esquerda incentiva a revisão do paradigma neoliberal e a crítica à estratégia de desenvolvimento até então vigente. Esse movimento devolve ao Estado importante papel na promoção de mudanças, especialmente nos campos econômicos e sociais (DINIZ, 2007 e 2011) e, assim como na década de 1930, ocupa espaço fundamental na resolução dos problemas desencadeados pelas crises econômicas sistêmicas.

Como demonstrado brevemente, o referencial teórico baseado na ideia de ciclo sistêmico, e dentro disso a relação centro-periferia, é um instrumental analítico relevante para entender não somente o período de reascensão do terceiro-mundismo e da ideologia do desenvolvimento na virada do século XXI, como também do refluxo,

14 Datam deste período os governos de Fujimori no Peru, Salinas no México, Carlos Menen na Argentina e Fernando Henrique Cardoso no Brasil, que, embora envolvidos com a implementação das orientaçóes políticas de Washington, o fizeram em ritmos e escalas diferentes.

15 Segundo Boschi e Gaitan (2015), eles vêm perdendo paulatinamente peso geopolítico no século XXI, vide a queda na participação do PIB mundial de 63\% em 2002 para 52\% em 2011.

${ }^{16}$ Brasil, Rússia, Índia, China e África do Sul.

${ }^{17}$ Fórum de Diálogo entre Índia, Brasil e África do Sul.

${ }^{18}$ A partir dos efeitos da crise da bolha imobiliária de 2008 nos EUA, novos contornos são dados à relação Estado-mercado. No centro, o Estado passa por uma revalorização no controle e regulação do mercado através, por exemplo, da compra de bancos privados como a Lehman Brothers. 
em certa medida, da agenda neoliberal. Fica patente aqui, sobretudo, que os processos de expansão-retraçáo do Estado respondem aos ciclos sistêmicos desde as origens da formação do Estado-Nação.

\section{Centralização e descentralização na teoria federativa}

No debate sobre federalismo, a centralização e a descentralização são tomadas como medidas ou parâmetros para escalonar e entender a dispersão de poder de cada país e em que medida os mesmos se distanciam ou aproximam-se de Estados unitários (modelo em que não há garantia de divisão de autoridade política entre os níveis de governo).

Com efeito, a origem e tradição dos estudos federativos se deram, de forma majoritária, por oposição às formas centralizadas e autoritárias edificadas no século XVII e fortalecidas durante o século XVIII. Essas formas concentradoras de poder econômico, político e simbólico (BOURDIEU, 2014) foram reconhecidas como potencialmente belicosas, propícias à tirania e à desintegração social.

Por essa razão, a definição de centralização não carrega grandes controvérsias. No debate federativo, podemos considerá-la como o processo de concentração de poder a nível federal, onde um ente estatal se coloca em um nível hierárquico acima dos demais, acumulando um conjunto de recursos, dentre eles recursos fiscais, legislativos, políticos e burocráticos que lhe garantem autonomia decisória.

Conforme demonstram Imannuel Wallerstein (1974) e Perry Anderson (2004), a centralização/concentração do poder se originou como resposta ao decadente sistema feudal e seus eixos de poder pulverizados/descentralizados, que entraram em crise no século XIV e exigiram uma saída do ponto de vista econômico e político. A saída econômica passou pela procura de novos territórios produtivos (grandes navegações) e estruturação do capitalismo primitivo com base na exploração (ANDERSON, 2004). Já a saída política, para viabilizar o novo sistema econômico, passou pela formação do Estado moderno e por um processo de concentração de recursos e autoridade antes dispersas, como o aparato de defesa, de arrecadação de impostos e formação da burocracia (WEBER, 2009).

$\mathrm{O}$ resultante desse processo formador do Estado-Nação foi um constante fortalecimento do poder nacional (central) ao longo dos séculos XVII até meados do século XX, consolidando-se como o eixo estruturador de toda a política, concentrador de todas as atribuições de um Estado.

Conforme demonstrou Abrúcio (2006), o fortalecimento dos aparatos centrais de governo foi progressivo. Do século XVII ao XIX foi estratégia para a 
colonização e, mesmo diante da doutrina do laissez-faire, foi arma no jogo geopolítico no contexto da busca por novos mercados. No século XX, após a crise de 1929 e, sobretudo, com a II Guerra Mundial, legitima-se como principal indutor do desenvolvimento econômico, provedor de políticas infraestruturais e de proteção social, através da intervenção estatal instituída pelo modelo keynesiano, adotado amplamente pelos países centrais, assim como em países periféricos, sob os moldes do desenvolvimentismo. Segundo Elazar (1991, p. 201), estabeleceu-se uma "sabedoria convencional" de que a centralização era um componente inevitável do Estado-Nação do século XX.

Nos países em desenvolvimento, especialmente nos países latino-americanos, a centralização do Estado foi base da estratégia de implantação do projeto desenvolvimentista, que tinha como grande objetivo superar o subdesenvolvimento, ou seja, modernizar e realizar a revolução capitalista nesses países através da atuação deliberada do Estado como indutor e/ou investidor direto (BIELCHOWSKI, 2004).

No início dos anos 1970, na esteira da crise capitalista, tendências contrárias à centralização começaram a se estabelecer no âmbito internacional e na academia, trazendo o debate sobre a descentralização e federalismo para o centro das análises da Ciência Política (ELAZAR, 1991). Em oposição à credibilidade gozada no pósguerra, o modelo de Estado interventor e centralizado passou a ser responsabilizado pela crise econômica e social observada. Em sua dimensão política, as formas centralizadas de poder passaram a ser associadas a práticas não-democráticas, clientelísticas e não-transparentes de gestão, por terem sido largamente utilizadas durante os períodos autoritários (ARRETCHE, 1996).

Com efeito, sob o ponto de vista normativo da reforma do Estado, a descentralização passou a ser apreciada como sinônimo de "boa prática de governança”. Como princípio de modernização da gestáo pública, foi associada à superação do passado interventor e à aproximação entre os centros decisórios e os cidadãos, entre a concepçáo e a execução das políticas públicas, promovendo maior eficiência, controle social, democracia e accountability dos governos em relação aos cidadãos (BOISIER, 1990; ARRETCHE, 1996). Dessa forma, os governos locais, que durante o período de welfare state foram responsabilizados pelas mais diversas práticas oligárquicas, são colocados no centro da nova reforma estatal defendida, passando a ser concebidos como berço de democracia, de práticas inovadoras e da eficiência em políticas públicas, verdadeiros laboratórios de "boas práticas" (FIGUEIREDO e LAMOUNIER,1996). 
Isso se deve ao fato de que, historicamente, o pensamento liberal associou poderes descentralizados e governos locais à democracia. Desde clássicos, como o livro de Alexis de Toqueville ("A democracia na América"), a descentralização é tomada como o modelo institucional de organização do Estado mais adequado para contemplar as demandas "que vem de baixo", promovendo a maior participação, eficiência na tomada de decisão e na implementação de políticas públicas.

De acordo com Abrúcio (2006), em muitos países desenvolvidos e de tradição centralizadora, como a Grã-Bretanha e França, adotaram-se reformas que repassaram poder ao plano local. Igualmente na Bélgica, Espanha e Itália, os governos subnacionais conquistaram forte autonomia. Nos Estados Unidos, país de histórica tradição federalista, houve também uma significativa renovação no discurso em prol da descentralização.

Nos países periféricos, em uma conjuntura em que muitos países estavam avançando na derrubada de regimes autoritários ${ }^{19}$, diversos Estados reforçaram seus pactos federativos em favor dos governos locais, desonerando o centro das responsabilidades pelo conjunto de políticas assumidas no período pretérito. Segundo estudo de Arretche (1996), dos 75 países em desenvolvimento, 63 implementaram reformas nas quais teria ocorrido um processo de transferência de poder político aos governos locais e para o terceiro setor, composto em geral por ONGs e entidades privadas, sobretudo na década de 1990. Nesse contexto, a descentralização foi adotada por distintos países do centro e periferia de maneira praticamente hegemônica, fazendo parecer que a "roda da história pendia para a descentralização" (ARRETCHE, 1996, p. 2). Autores como Boisier (1990), Cao e Vaca (2006), examinando a aplicação do conceito, afirmaram que nesse contexto histórico a descentralização se tornou uma "panaceia universal".

Se do ponto de vista normativo a descentralização gozou de certa hegemonia nesse período, sua definição enquanto conceito não é simples, atravessando áreas e campos distintos e podendo se concretizar de diferentes formas. Peters (2005) entende a descentralização como uma estratégia geral onde o padrão dominante foi mover a política e os controles administrativos à distância do centro político do governo.

19 Entre 1980 e 1990, mais de uma dezena de países latino-americanos viveram a transição democrática: na América do Sul, por exemplo, o fim do regime militar ocorreu em 1982, na Bolívia; em 1983, na Argentina; em 1984, no Uruguai; em 1985, no Brasil e em 1988 no Chile. 
No debate federativo, podemos considerar a descentralização como um processo que dispersa ou distribui o poder que estava anteriormente concentrado (PETERS, 2005; ELAZAR, 1991; WATTS, 2006). Ou seja, trata-se da dispersão de poder decisório, constitucionalmente estruturado (ELAZAR, 1991), que capacita as instâncias políticas subnacionais e seus eleitores a tomarem decisóes sobre seus territórios, sua alocação de recursos e suas políticas públicas (SOUZA, 2006). Deriva, portanto, de um arranjo constitucional e institucional que garante autonomia e responsabilidades partilhadas.

Corroborando em termos gerais com tal definiçáo, Falleti (2006, p. 60) conceitua a descentralização como um processo de reforma do Estado composto por um conjunto de políticas públicas que transfere responsabilidades, recursos ou autoridade de níveis mais elevados de governo para níveis inferiores, no contexto de um tipo específico de Estado. Em geral, a descentralização em Estados federativos é tratada em três âmbitos pela literatura: a política, a fiscal e a administrativa.

Para aferir a descentralização, é necessário considerar duas dimensões: constitucional, que estipula a divisão de competências de cada ente constitutivo (autonomia política, fiscal e administrativa formal para desempenhá-las); e a real, amparada no grau de autonomia concreta que as unidades constituintes logram para desempenhar um papel significativo no processo decisório do dito nível. Autonomia, por essa lógica, pode ser considerada como a liberdade e capacidade que os governos possuem para decidir e implementar suas políticas públicas, sem interferência dos demais níveis de governo. Trata-se, portanto, de um importante indicador da descentralização concreta nos Estados federativos. Conforme evidenciaram Watts (2006) e Arretche (2012), nem sempre a garantia de autonomia federativa transmitida pelas constituiçôes se converte em autonomia decisória real. Segundo essa lógica, políticas públicas aparentemente descentralizadas no nível da execução podem ser centralizadas no nível de decisão.

Para esses autores é o nível de decisão e não de implementação que define o grau de centralização ou descentralização de uma política pública ou de uma federação. Watts (2006) utiliza o caso japonês para elucidar essa premissa, afirmando que naquele país há a descentralização administrativa apenas no âmbito da execução, na medida em que as decisões principais são dadas no nível central. Arretche (2012), na mesma linha argumentativa, mostrou o caso dos municípios brasileiros e seus constrangimentos estruturais (desigualdades regionais e baixa capacidade arrecadatória) e institucionais (referentes à baixa capacidade de os níveis locais 
legislarem sem interferência do nível federal e terem corpo burocrático adequado) para lograr uma autonomia real.

No início do século XXI, passado o período de euforia com as reformas, em decorrência da conjuntura crítica em termos econômicos e sociais e do refluxo do ideário neoliberal, pesquisas empíricas passaram a balizar os resultados da descentralização em diferentes países (ARRETCHE, 1996 e 2012; CAO e VACA, 2006) e a fazer a crítica desse modelo como "fórmula" para resolução dos problemas públicos, como a ineficácia das políticas públicas e o clientelismo.

Para Arretche (1996), a análise sobre as mazelas e benefícios trazidos concretamente por cada um desses formatos institucionais na implementação de políticas públicas parece ter sido uma discussão menor do que foi a dimensão ideológica que permeou este tema na década de 1990. Assumindo a premissa apresentada pela autora, não há porque tratar a discussão centralizaçãodescentralização a partir de um viés normativo, tampouco creditar a um desses modelos qualidades e defeitos intrínsecos. Assim, os ideais democráticos ligados às políticas públicas devem ser associados menos à escala ou nível de governo encarregado da sua gestão, e mais ao seu conteúdo e à natureza das instituições que, em cada nível de governo, devem processar as decisôes.

Acrescenta-se, ainda, a constatação de que tampouco a eficácia das políticas depende do nível de governo responsável pela sua formulação ou implementação, mas antes de suas capacidades estatais historicamente construídas e, sobretudo no caso de estados federados, à capacidade de coordenar açóes e políticas que atendam aos interesses mais gerais. A maior accountability dos governos em relação aos cidadãos não depende, igualmente, apenas do nível de governo, mas da capacidade de se criar canais participativos/deliberativos e de controle social.

No século XXI, mesmo assim, a re-centralização foi adotada, não como uma oposição ao receituário neoliberal de descentralização, mas como forma de garantir o controle sobre o processo de desenvolvimento, especialmente em relação às diversas políticas sociais (combate à fome, assistência social, combate à pobreza, garantia de emprego, entre outras). A garantia de formas mais pulverizadas de execução nos níveis locais, associadas a um planejamento central dessas políticas, possibilitou um processo de diminuição das desigualdades, da fome e da pobreza na América Latina como nunca antes visto. A centralização do que é considerado estratégico para o desenvolvimento, portanto, relaciona-se às próprias necessidades que surgem em cada momento do capitalismo. Se o processo de crise sistêmica iniciado nos anos 1970 e aprofundado com o neoliberalismo nos anos 1980 e 1990 promoveu crises sociais e 
piora nos indicadores de bem-estar, tornou-se necessário, ao invés de um planejamento rigoroso de política econômica, o tratamento de questóes sociais na base, impedindo o ciclo retroalimentador da miséria.

\section{Considerações finais}

Este artigo, a partir de uma revisão teórica sobre Estados federativos, pretendeu ofertar uma visão crítica a respeito dos processos de centralização e descentralização, problematizando a premissa de que tais modelos respondem unicamente aos legados internos, construídos através das trajetórias peculiares de cada Estado. Com o aporte teórico oriundo da economia e das relaçóes internacionais, procuramos demonstrar que os ciclos econômicos externos não afetam apenas aspectos conjunturais de centro e periferia, mas as próprias instituiçóes políticas, como a federação. Nesse sentido, as federações, sobretudo as latino-americanas, como buscamos exemplificar, são mutáveis e adotam formas mais centralizadas ou descentralizadas conforme sua trajetória própria, mas sobretudo devido aos impulsos dados pelos movimentos cíclicos do sistema capitalista, que tende a lhes apontar um "sentido".

As teorias federativas, por outro lado, evoluíram de acordo com o padrão dominante em cada época em relação à dualidade realismo/intervencionismo versus liberalismo. Tradicionalmente associada aos estados autoritários e hobbesianos, a centralização é recuperada de acordo com a conveniência, com a quantidade de capital disponível e o ciclo de acumulação predominante, bem como a existência de crises econômicas que promovam novos padrões de percepção sobre sua superação. As respostas às crises do capitalismo são sempre aquelas convenientes aos interesses dos países centrais, sendo transportadas através de "engenharias teóricas" para a periferia, que as adapta, ou não, à sua realidade. No século XXI, com a emergência do mundo multipolar e a recuperação econômica da periferia, não mais os modelos forjados no centro são tidos como corretos, adequados ou bons em termos valorativos (vide a própria noção de descentralização).

A partir desses apontamentos, é possível entender que as mudanças estatais ocorridas, em especial, nos países em desenvolvimento, não são apenas decorrência de suas rotas institucionais ou de escolhas de elites autônomas, mas decorrem, sobretudo, da alta correlação existente entre ciclos econômicos e políticos no centro da economia mundial, o que afeta os movimentos de expansão-retração da intervenção estatal nos modernos Estados-nação e suas instituições. 
Assim, se de um lado a teoria institucionalista permite analisar as rotas institucionais dos federalismos, respondendo às diferenças observadas entre países, sobretudo latino-americanos ${ }^{20}$, é a teoria dos ciclos sistêmicos que irá subsidiar a explicação acerca da relativa sincronia ${ }^{21}$, no tempo e no conteúdo, das mudanças estatais nesses países, especialmente em relação aos movimentos de centralização e descentralização de suas relações federativas.

- Luciana Pazini Papi é Professora adjunta do departamento de Ciências Administrativas da Universidade Federal do Rio Grande do Sul (UFRGS). Doutora em Ciência Política pela UFRGS/ Universidade Torcuato Di Tella. É Pesquisadora Coordenadora do Núcleo de Pesquisa em Gestão Municipal - NUPEGEM/UFRGS. Email - luciana.pazini@ufrgs.br, luppapi@yahoo.com.br

Klei Medeiros é Professor de Relações Internacionais na Pontifícia Universidade Católica de Minas Gerais (PUC-Minas), doutorando em Relações Internacionais no PPG San Tiago Dantas (Unesp-Unicamp-PUC-SP) e mestre em Ciência Politica na Universidade Federal do Rio Grande do Sul (UFRGS). É membro do Núcleo Brasileiro de Estratégia e Relações Internacionais (NERINTUFRGS) e do Grupo de Pesquisa sobre Potências Médias (GPPMPUC-Minas). E-mail: kleimedeiros@gmail.com.

\footnotetext{
${ }^{20}$ Como o caso de Brasil e Argentina, analisado em detalhe na tese de doutorado de Papi (2017). ${ }^{21}$ José Luis Fiori (2007) defende a ideia de que a América Latina, a despeito de sua heterogeneidade interna, desde suas "guerras de formação" no século XIX, tem se movido de maneira mais ou menos sincrônica aos padróes de desenvolvimento engendrados pelo centro. $\mathrm{O}$ autor destaca os contextos que apontam esta convergência na região: o momento da integração agrário-exportadora à economia industrial europeia a partir de 1870; o movimento de inversão de exportaçóes na década de 1930 e a reação desenvolvimentista; a instalação de golpes militares e regimes ditatoriais a partir da década de 1960 e 1970; o processo de redemocratização a partir de 1980; por fim, a adoção nos anos 1990 de políticas do Consenso de Washington, que com maior ou menor intensidade impuseram na região um movimento de desregulamentação econômica, privatização dos bens nacionais e um conjunto de reformas estatais.
} 


\section{Referências}

ABRÚCIO, Fernando Luiz. Para além da descentralização: os desafios da coordenação federativa no Brasil. In: FLEURY, Sônia (Org.). Democracia, descentralização e desenvolvimento: Brasil e Espanha. Rio de Janeiro: FGV, 2006. p. 77-125.

ANDERSON, Perry. Linhagens do Estado absolutista. São Paulo: Brasiliense, 2004.

ARRETCHE, Martha. Democracia, federalismo e centralização no Brasil. Rio de Janeiro: FGV, 2012. . Relaçóes federativas nas políticas sociais. Educação \& Sociedade, v. 23, n. 80, p. 25-48, set. 2002.

- Mitos da descentralização: maior democracia e eficiência nas políticas públicas? Revista Brasileira de Ciências Sociais, v. 11, n. 31, p. 44-66, 1996.

ARRIGHI, Giovanni. Adam Smith em Pequim: Origens e fundamentos do século XXI. São Paulo: Boitempo, 2008. . A Ilusão do Desenvolvimento. Petrópolis, RJ: Vozes, 1997

. O Longo Século XX. São Paulo: Editora UNESP, 1996.

ARRIGHI, Giovanni.; SILVER, Beverly. Caos e Goavernabilidade no moderno sistema mundial. Rio de Janeiro: Contraponto, 2001.

BIELCHOWSKI, Ricardo. Pensamento econômico brasileiro de 1930 a 1964. Rio de Janeiro: Contraponto, 2004.

BOISIER, Sergio. La descentralizacion: un tema difuso y confuso. Santiago do Chile: Instituto Latinoamericano y del Caribe de Planificación Económica y Social (ILPES/ONU), 1990. (Serie Ensayos).

BOSCHI, Renato; GAITAN, Flávio. Capacidades estatais e a dimensão político-institucional: um modelo analítico para focalizar as trajetórias recentes de Brasil e Argentina. In: BOSCHI, Renato; BUSTELLO, Santiago. Brasil e Argentina: Políticas e trajetórias de desenvolvimento. Rio de Janeiro: E- papers, 2015.

BOURDIEU, Pierre. Razóes práticas: sobre a teoria da ação. São Paulo: Papirus, 2014.

BRAUDEL, Fernand. The perspective of the World. Nova York: Harper e Row, 1984.

BRESSER-PEREIRA, Luiz Carlos. Construindo o Estado Republicano. Rio de Janeiro: FGV, 2009.

- Macroeconomia da Estagnação. Crítica da ortodoxia convencional no Brasil pós 1994. São Paulo: Ed. 34, 2007.

CAO, Horacio; VACA, Josefina. El fracasso del processo descentralizador argentina: una aproximación desde la crítica a sus supostos conceptuales. Nómadas - Revista crítica de ciencias sociales y jurídicas, v. 14, n. 2, 2006.

CARNOY, Martin. Estado e Teoria Política. 2. ed. Campinas: Papirus, 1988

CHANG, Haa-Jo. Maus Samaritanos: O mito do livre comércio e a história secreta do capitalismo. Rio de Janeiro: Campus/Elsevier, 2008.

DINIZ, Eli. O contexto internacional e a retomada do debate sobre desenvolvimento no Brasil contemporâneo (2000/2010). Dados, v. 54, n. 4, p. 493-532, 2011.

Globalização, Estado e Desenvolvimento. Dilemas do Brasil no Novo Milênio. Rio de Janeiro: FGV, 2007.

ELAZAR, Daniel. Exploring federalism. Alabama: University of Alabama Press, 1991. 
FALLETI, Tulia. Efeitos da Descentralização nas relaçôes intergovernamentais: O Brasil em Perspectiva Comparada. Sociologias - Sociedade e Políticas Públicas, ano 8, n. 16, p. 46-85, jul./dez. 2006

FIGUEIREDO, Rubens.; LAMOUNIER, Bolívar. As cidades que dão certo: Experiências inovadoras na administração pública brasileira. Brasília: MH Comunicação, 1996.

FIORI, José Luiz. Olhando para esquerda Latino-americana. In: DINIZ, Eli (Org). Globalização, Estado e Desenvolvimento. Dilemas do Brasil no Novo Milênio. Rio de Janeiro: FGV, 2007. p. $97-$ 125.

FRANK, André Gunder. Acumulação dependente e subdesenvolvimento: repensando a teoria da dependência. São Paulo: Ed. Brasiliense, 1980.

FUKUYAMA, Francis. The end of History and the last man. Nova York: Free Press, 1992.

HALL, Anthony; MIDGLEY, James. Social policy for Development. London: Sage, 2004.

HALL, Peter A.; TAYLOR, Rosemary C. R. As três versóes do neo-institucionalismo. Lua Nova, n.58, p. 193-223, 2003.

HARVEY, David. Condição Pós Moderna. São Paulo: Edições Loyola, 2005.

LENIN, Vladmir Ilitch. The state and Revolution. Peking: Foreing Language Press, [1917] 1965.

LIJPHART, Arend. Modelos de democracia: desempenho e padróes de governo em 36 democracias. Rio de Janeiro: Civilização Brasileira, 2003.

MACHADO, Luiz Toledo. A teoria da dependência na América Latina. Estud.av., v. 13, n. 35, p. 199-215, abr. 1999. Disponível em: <http://www.scielo.br/scielo.php?script=sci_arttext\&pid=S0103-

40141999000100018\&lng=en\&nrm=iso >. Acesso em: 30 abr. 2019.

MILANI, Carlos Roberto Sanchez. Desenvolvimento e Cooperação Internacional: relação de poder e política dos Estados. Salvador: Edufba, 2014.

MILIBAND, Ralph. O Estado na sociedade capitalista. Rio de Janeiro: Zahar, 1972.

PAPI, Luciana. A Dinâmica Federativa de Brasil e Argentina: Estudo comparado sobre as mudanças nos desenhos de formulação e implementação de políticas de combate à pobreza e de assistência social. 2017. 236f. Tese (Doutorado em 2017) - Programa de Pós-Graduação em Ciência Política, Universidade Federal do Rio Grande do Sul (UFRGS), Porto Alegre, 2017.

PETERS, B. Guy. The Search for Coordination and Coherence in Public Policy: Return to the Center? [unpublished paper]. Department of Political Science, University of Pittsburgh, 2005. Disponível em: <http://userpage.fu-berlin.de/ffu/akumwelt/bc2004/download/peters_f.pdf>. Acesso em: 26 jun. 2019.

PIERSON, Paul. Politics in time: history, institutions, and social analysis. Princeton: Princeton University Press, 2004.

POULANTZAS, Nicos. Poder político y clases sociales en el Estado capitalista. México, D. F.: Siglo Veintiuno, [1968] 2007.

SOUZA, Celina. Desenho constitucional, instituições federativas e relações intergovernamentais no Brasil pós-1988. In: FLEURY, Sonia (Org). Democracia, Descentralização e desenvolvimento: Brasil e Espanha. Rio de Janeiro: FGV, 2006.

WALLERSTEIN, Imannuel. The modern world-system: Capitalist agriculture and the origins of the European world-economy itz the 16th. century. New York: Academic Press, 1974.

WATTS, Ronald. Sistemas federados comparados. Barcelona: Ediciones Juridicas y Sociales, 2006. 
WEBER, Max. Economia e sociedade. Brasília: Editora da UNB, 2009.

Texto recebido em 10 de janeiro de 2019.

Aprovado em 30 de abril de 2019. 